\title{
A Review on Intellectual Capital Concepts as a Base for Measuring Intangible Assets of Collaborative Networks
}

\author{
Raul Rodriguez-Rodriguez, Juan-Jose Alfaro-Saiz, and Maria-Jose Verdecho \\ Universitat Politècnica de Valencia, Departamento de Organización de Empresas, \\ Camino de Vera sn, 46022 Valencia, Spain \\ \{raurodro, jalfaro, mverdecho\} @cigip.upv.es
}

\begin{abstract}
This work presents a revision of the main definition and significances of the term Intellectual Capital, as it is an important issue of study. Once the main scientific works related to Intellectual Capital are presented and their main contributions highlighted, this work shows how it has been attempted to measure the Intellectual Capital at both individual enterprises and collaborative networks, as a source of meaningful information to make decisions. The paper evidences the lack of works that have successfully dealt with measuring Intellectual Capital at the collaborative networks level, highlighting the main barriers and what a proper measuring framework should address at this level.
\end{abstract}

Keywords: Intellectual capital, collaborative networks, measurement.

\section{Introduction}

A company's capability to create value depends on its ability to implement strategies that respond to market opportunities by exploiting their internal resources and capabilities [1]. Therefore, managers need to understand what the key internal resources and drivers of performance in their organisations are. Traditionally, those resources were physical, such as machines and equipments, and financial capital. In today's economy traditional tangible assets seem to become increasingly transient and rarely provide a long-term competitive advantage. This reflects the belief that intangibles assets are a fundamental resource of corporate growth and organizations need to put into work procedures for managing their intangible assets. In the last years, the concept of Intellectual Capital (IC) has emerged as a key to analyse and evaluate the intangible assets of organizations.

\section{Literature Review}

In the last two decades, several models have been developed for managing the IC. All of them attempt to identify, classify, measure and manage the company's IC. Some models are focused on the global IC of the company such as the Skandia Navigator [2], the Intangible Assets Monitor [3]. On the other hand, other frameworks are focused on the intangibles related to the defined strategies such as [4] or the Intellectual Capital Management System. However, none of these models implement 
or suggest the integration within a performance measurement system, which would contribute the advantages of its use.

In the literature, the concept of IC has been defined from different management perspectives as shown in Table 1. For instance, accounts prefer to talk about intangibles and according to [5], define them as "non-financial fixed assets that do not have physical substance but are identifiable and controlled by the entity through custody and legal rights". From a human resource (HR) perspective, IC refers to skills, knowledge, and attitudes of employees. From a marketing perspective, intangibles such as brand recognition and customer satisfaction are at the heart of business success, whereas from at the information technology (IT) perspective, intangibles are seen as being software applications and network capabilities (for an indepth discussion of the different perspectives on IC please refer to [6]). As shown by the above definitions, there is no agreement upon what constitutes a good or sufficient definition of IC. Finally, IC is an important theme in different disciplines and is looked at from different perspectives such as economics, strategic management, finance, accounting, reporting and disclosure, human resources, and marketing and communication. However, there are few works developed related to the IC in the field of performance measurement.

Table 1. Main definitions of Intellectual Capital

\begin{tabular}{ll}
\hline References & Definition \\
\hline$[7]$ & It is set up by intangible property and intangible resources. \\
[8] & It is knowledge that can be converted into value. \\
It is the result of four main components, which are the \\
market assets, human-centred assets, intellectual property \\
assets and infrastructure assets. \\
It is related to three categories of intangible assets: internal \\
structure, external structure and human competence. \\
It is composed of (and generated by) a thinking part, i.e. the \\
human capital, and a non-thinking part, i.e. the structural \\
capital. \\
It is an intellectual material that has been formalised, \\
captured and leveraged to produce a higher-valued asset. \\
It is the sum of human and structural capital. In more detail it \\
involves applied experience, organizational technology, \\
customer relationships and professional skills that provide an \\
organization with a competitive advantage in the market. \\
It is a concept under which are classified all organization \\
intangible resources as well their interconnections
\end{tabular}

The Intellectual Capital Management Models are focused on the establishment of one definition of IC, the components or dimensions of its structure, the intangible assets that belong to each component or dimension, and the indicator used to measure the identified intangible assets. Some models, as result of their activities, elaborate one report with two proposals, one as internal management tool and the second as external spreading tool of information for informing to the stakeholders about the real value of the company and not only about its financial value. Only some of the recently 
developed models of IC identify the need of linking the intangible assets with the strategy of the company, such as [4]. Such a project was the first model that proposed the identification of the strategic objectives of the company and the critical intangible assets related to each of these strategic objectives as one of the main steps of this project. Moreover, the RICARDA project establishes that the first step to create a report of Intellectual Capital for Regional Networks o Clusters is the definition of the regional network or cluster's objectives in medium and long term and the second step is concerning to the identification of each intangible assets that affect them.

\section{Measuring Intellectual Capital}

\subsection{Enterprise Level}

Nowadays, IC has become a determinant resource for enterprise to retain and improve competitive advantages. Because of its abstract nature, the IC is very difficult to measure, having become a challenge for business managers to evaluate the performance of IC effectively.

[13] identified as benefits of IC measurement firstly the identification and mapping of intangible assets, which allows the company knowing its resources of competitive advantages on the future. Secondly, the recognition of knowledge flow patterns within the company. The last two benefits drive to the prioritization of critical knowledge issues, which allow the acceleration of learning patterns within the company thanks to the best practice identification and diffusion across the company, by presenting a strong business case for the best practice. Besides, the measurement of the IC permits a constant monitoring of asset value as well as to find ways of increasing the value of the company and the understanding of how knowledge creates interrelationships and increases innovation. From the point of view of the employees, the benefits are with regard to the increasing of collaborative activities and a knowledge sharing culture as a result of increased awareness of the benefits of knowledge management. Also the employee self-perception of the organization and their motivation are increased. Finally, it creates a performance-oriented culture.

Measurement of IC will result in significant benefits to the organization that will help to determine business strategy, process design as well providing competitive advantage.

Additionally, [12] carried out an exhaustive literature review in which he highlighted the following main limitations in the existing measurement systems:

- The existing approaches relate to the organization as a whole and do not account for individual departments or knowledge workers.

- They do not balance past-orientation with future predictions, or quantitative financial measures with qualitative perceptual and process measures.

- Behavioural dynamics and its impact on organizational economics are not measured.

- There is no system for measuring process effectiveness in capturing tacit knowledge transfer. 
At present, measuring a company's Intellectual Capital is quite common. According to Nordic survey, two thirds of Finnish companies measure their Intellectual Capital regularly. Despite the fact that measuring Intellectual Capital is considered important, only 35 percent of the companies know how Intellectual Capital should be measured and reported [14]. Although different measurement systems for measuring Intellectual Capital have been developed, none of them has been accepted for common use. According to [3] the approaches for measuring intellectual capital fall into four categories: Direct Intellectual Capital Methods (DIC), Market Capitalization Methods (MCM), Return on Assets Methods (ROA) and Scorecard Methods (SC). The methods offer different advantages and disadvantages.

Scorecard Methods in particular have been developed as a tool for management and although all the scorecard methods have many similarities, they can be categorized into two different types: the (traditional) balanced performance measurement methods and Intellectual Capital measurement methods. The balanced performance measurement frameworks, e.g. the Balanced Scorecard [15] and the Performance Pyramid [16], have been developed for measuring and managing an organization's performance from several perspectives. IC is often related to one or more of these perspectives. However, in the IC measurement methods, e.g. the Skandia Navigator [2] and the Intangible Assets Monitor [3], the main rationale is the measurement of IC. Financial and other physical assets are not paid as much attention as the Intellectual-Capital-related factors.

Kaplan y Norton [17] indicated that the intangible assets are hard for competitors to imitate, which makes them a powerful source of sustainable competitive advantage. The Learning and Growth Perspective of the Balances Scorecard has long been considered its weakest link, and Kaplan and Norton admitted it . To improve this the authors included in this perspective the intangibles assets essentials for implementing any strategy, which are classified in three categories: Human Capital (the skills, talent and knowledge that a company's employees possess), Information Capital (the company's database, information systems, networks and technology infrastructure) and Organizational Capital (the company's culture, its leadership, how aligned its people are with its strategic goals and employee's ability to share knowledge). Additionally, and to link these intangible assets to the company's strategy and performance, these authors developed a tool called "strategic map".

Although the terminology used to describe and categorize intangible assets is far from being cohesive at the detailed level, there has recently been a general convergence towards a three-pronged framework consisting of Human Capital, Organizational (or Structural) Capital and Relational Capital [4]. Therefore, it is not clear why Information Capital is considered by Kaplan and Norton separated from Organizational Capital as most of the researches on this field agree.

As well, the concept of Relational Capital is completely missing from Kaplan and Norton's definition of intangible assets. The Balanced Scorecard includes a Customer Perspective and it could be argued that customer relationships could be included into this perspective. In fact, Kaplan and Norton [17] argue that this perspective should contain the customer value proposition. Even if relationships might be included the issue remains that according to Kaplan and Norton's definition of intangibles assets, Relational Capital is not included, which defies the views of most researchers working in this field. 
At this point, several gaps have been identified in the above literature review such as the lack of consensus among the researchers and the practitioners about the definitions of IC, the IC components and the IC indicators. Many and various have been the attempts to measure the intangible assets of the companies through different IC models. Kaplan and Norton, instead of creating a new model to measure the intangible assets, have integrated the measurement of the intangible assets within their Balanced Scorecard. Several researchers have criticized this attempt, having being identified several gaps in the way they have done such a merge.

\subsection{Collaborative Network Level}

On the other hand, and looking at the collaborative networks ambit, all these research gaps are present, among others. Collaboration implies factors such as trust, equity, coherence, visibility, contradictory objectives, or communication issues that are beyond the individual enterprise's problems [18]. This fact makes much more difficult to measure performance of collaborative networks from both a tangible and intangible point of view. Measuring intellectual capital is still in its early steps, as highlighted above and, at the collaborative ambit, even more.

Some authors have recently dealt with the issue of measuring performance at collaborative contexts [18, 19, 20, 21, 22]. However, none of these works have deeply stated how to measure IC at collaborative networks levels. However, by bringing up the main conclusions together, it is possible to affirm that it is still lacked a method that should:

- Establish the linkage between the tangible and the intangible assets of the CN. This is such a difficult task but it needs to be done in order that $\mathrm{CN}$ decisionmakers will be able to clearly know to what extent the achievement of a certain degree of IC within the $\mathrm{CN}$ is impacting over the fulfillment of the CN's strategic objectives. This could be done by applying either subjective (surveys, Multi-Criteria Decision-Aid Techniques) or objective techniques (statistical techniques analyzing historical data from the $\mathrm{CN}$ ).

- Consider the specific requirements of IC in $\mathrm{CN}$ as compared to individual enterprises. Nowadays, individual enterprises take part in several supply chains/CNs and, therefore, it is very likely that some of these CNs will have contradictory objectives. Then, the decision-making mechanisms of each individual enterprise are internal and not known to a single CN. Such a lack of knowledge of how the individual enterprise is going to decide can be a serious barrier. Besides, contradictory objectives will lead to discussions within the $\mathrm{CN}$ and ways that will lead to consensus should be waved. Some collaborative factors have been mentioned above and these are of particular relevance to $\mathrm{CN}$. How to deal with them in different scenarios and regarding IC is still lacked.

- From the last one, it would be desirable to find out to what extent are linked together both different IC intensity degrees and the achievement of one or more important collaborative factors. For instance, to study how different levels of IC in two enterprises of a $\mathrm{CN}$ affects to their cycles of trust-distrust. 
To sum up, it is possible to affirm that, as result of the analysis of the identified gaps on the measurement of the intangible assets, a new approach is necessary at both the individual enterprise and the collaborative network context with the aim of improving this research field.

\section{Conclusions}

Recently, the thematic of Intellectual Capital has emerged as a key issue to analyse and evaluate the intangible assets of organizations. Both practitioners and academics agree on the fact that before to measure Intellectual Capital, it is necessary to find a common definition of what Intellectual Capital is. Then, this paper firstly presents the main Intellectual Capital definitions. Then, it highlights the main advantages of measuring Intellectual Capital in organisations and, extensively, in collaborative networks, concluding that there is still a huge research field to be filled in on this area.

\section{References}

1. Penrose, E.T.: The theory of the growth of the firm. John Wiley, New York (1959)

2. Edvinsson, L., Malone, M.S.: IC: the Proven Way to Establish Your Company's Real Value by Measuring Its Hidden Values. Piatkus, London (1997)

3. Sveiby, K.E.: The New Organizational Wealth: Managing \& Measuring Knowledge-Based Assets. Berrett-Koehler Publishers, Inc., San Francisco (1997)

4. MERITUM Guidelines. Guidelines for Managing and Reporting on Intangibles, Madrid (2002)

5. International Accounting Standards Board (IASB). Intangible Assets, International Accounting Standards No. 38 revised. IASB, London (2004)

6. Marr, B.: Perspectives on IC: Multidisciplinary Insights into Management, Measurement, and Reporting. Elsevier, Boston (2005)

7. Hall, R.: The strategic analysis of intangible resources. Strategic Management Journal 2, 135-137 (1992)

8. Edvinsson, L., Sullivan, P.H.: Developing a model for managing intellectual capital. European Management Journal 14, 356-365 (1996)

9. Brooking, A.: IC: Core Assets for the Third Millennium Enterprise. Thompson Business Press, London (1996)

10. Roos, J., Roos, G., Dragonetti, N.C., Edvinsson, L.: IC: Navigating the New Business Landscape. Macmillan, London (1997)

11. Stewart, T.A.: IC: The New Wealth of Organisations. Doubleday/Currency, New York (1997)

12. Bontis, N., Dragonetti, N.C., Jacobson, K., Roos, G.: The knowledge toolbox: a review of the tools available to measure and manage intangible resources. European Management Journal 17, 391-402 (1999)

13. Kannan, G., Aulbur, W.G.: IC: Measurement effectiveness. Journal of IC 5, 389-413 (2004)

14. Nordika Project. Measuring and Reporting IC: Experiences, Issues, and Prospects. OECD, Paris (2002)

15. Kaplan, R.S., Norton, D.P.: The Balanced Scorecard - Measures that Drive Performance. Harvard Business Review, 71-79 (January/February 1992) 
16. Lynch, R.L., Cross, K.F.: Measure Up! The Essential Guide to Measuring Business Performance. Mandarin, London (1991)

17. Kaplan, R.S., Norton, D.P.: Measuring the Strategic Readiness of Intangible Assets. Harvard Business Review 82, 167-176 (2004)

18. Alfaro Saiz, J.J., Rodriguez-Rodriguez, R., Ortiz Bas, A., Verdecho, M.J.: An information architecture for a performance management framework by collaborating SMEs. Computers in Industry 61, 676-685 (2010)

19. Busi, M., Bititci, U.S.: Collaborative performance management: present gaps and future research. International Journal of Productivity and Performance Management 55, 7-25 (2006)

20. Angerhofer, B.J., Angelides, M.C.: A model and a performance measurement system for collaborative supply chains. Decision Support Systems 42, 283-301 (2006)

21. Gaiardelli, P., Saccani, N., Songini, L.: Performance measurement of the after-sales service network - Evidence from the automotive industry. Computers in Industry 58, 698-708 (2007)

22. Gruat, F.A., La Forme, V., Campagne, J.P.: A Framework to analyse Collaborative Performance. Computers in Industry 58, 687-697 (2007) 